\title{
CHANGES IN LANDSCAPE PATTERN OF WETLAND AROUND HANGZHOU BAY
}

\author{
Wenpeng Lin ${ }^{1}$, Yuan $\mathrm{Li}^{2}$, , Dan $\mathrm{Xu}^{2}$, Ying Zeng ${ }^{1}$ \\ ${ }^{1}$ College of Tourism, Shanghai Normal University, Shanghai, China-(linwenpeng, nj2014)@163.com \\ ${ }^{2}$ College of Life and Environment Science, Shanghai Normal University, Shanghai,China-(yuxuan_2865,fannyaugust)@163.com
}

KEY WORDS: Remote sensing, Wetland, Landscape pattern, Hangzhou Bay

\begin{abstract}
:
Hangzhou Bay is an important estuarial coastal wetland, which offers a large number of land and ecological resources. It plays a significant role in the sustainable development of resources, environment and economy. In this paper, based on the remote sensing images in 1996, 2005 and 2013, we extracted the coastal wetland data and analyzed the wetland landscape pattern of the Hangzhou Bay in the past 20 years. The results show that: (1) the area of coastal wetland is heading downwards in the recent decades. Paddy field and the coastal wetland diminish greatly. (2) the single dynamic degree of wetland of the Hangzhou Bay displays that paddy fields and coastal wetlands are shrinking, but lakes, reservoirs and ponds are constantly expanding. (3) the wetland landscape pattern index shows that total patch area of the coastal wetland and paddy fields have gradually diminished. The Shannon diversity index, the Shannon evenness index as well as the landscape separation index of the coastal wetlands in the Hangzhou Bay increase steadily. The landscape pattern in the study area has shown a trend of high fragmentation, dominance decreases, but some dominant landscape still exist in this region. (4) Urbanization and natural factors lead to the reduction of wetland area. Besides the pressure of population is a major threat to the wetland. The study will provide scientific basis for long-term planning for this region.
\end{abstract}

\section{INTRODUCTION}

Wetlands are the transitional ecosystems which exist between land forms and water bodies with unique hydrology, soils, vegetation and biological characteristics. They are well known as the "biological supermarkets" and "nature's kidney" of the earth. The wetland is one of the most important human living environment (Fang et al., 2011; Costanza et al., 1997; Batzer et al., 2006; Liu et al., 2009; Kayastha et al., 2012), which provides various valuable services in ecology (Zedler et al., 2005; Ghermandi et al., 2010; Blackwell et al., 2011; De et al., 2011; Horowitz et al., 2011). A plenty of investigations (Bai et al., 2005; Ding et al., 2004) become a critical topic in wetland research which focus on the changes of wetland landscape pattern in recent years. Spatial statistics, transition matrix, landscape index, cellular automaton and other simulation methods are mainly used in current research on landscape patterns. Its research-scale concentrated on two aspects of spatial and temporal heterogeneity (Fan et al., 2014). Quantitative analysis of landscape index is used to study the characteristics of wetland landscape patterns and its evolution. The landscape index and landscape dynamics model are mainly included. Remote sensing images of the study area are acquired and processed subsequently to obtain the distribution of wetland in Hangzhou Bay (1996, 2005 and 2003, respectively). The final results of the dynamic change of wetland landscape characteristics are achieved by using the related software (Niu et al., 2004).

Hangzhou Bay is located in the southern of the Yangtze River Delta. With the rich tidal wetland resources and convenient panort shipping transport facilities, its urbanization and industrialization becomes faster. However, the land use cover change shifts gradually and affects the wetland resources due to the rapid economic development and the increased population.
In order to provide the basis for wetland conservation in Hangzhou Bay, the Hangzhou Bay was selected as the study area on the basis of previous research results in this paper. The wetland landscape patterns in Hangzhou Bay were analyzed through the three remote sensing data in the year of 1996, 2005 and 2013.

\section{MATERIALS AND METHODS}

\subsection{Study Area}

The study area is located in the south and north shore around Hangzhou Bay, Jiuduansha, Pudong new area, and Jinshan, Fengxian district are on the north shore, Pinghu, Haiyan, Shangyu, Cixi and some other regions in the Zhejiang Province are included on the south shore. The method to define the study area: the land area is divided by the administrative districts, while in the sea area, the $6 \mathrm{~m}$ waterline is used as the threshold to define the inshore water. The typical estuary "Hangzhou Bay” upstream accesses the Qiantang River, downstream on the verge of the East China Sea (Fig.1). The northern and southern shores of Hangzhou Bay have been eroded and silted for a long time. The southern bank is the Ningshao plain while the northern bank is the southern margin of the Yangtze River Delta. The beaches are wide, with the rich wetland resources. According to the official announcement published by National Bureau in 2013, the six cities around Hangzhou Bay were included in the top hundred cities about overall strength in China. Therefore, Hangzhou Bay area becomes one of the most important domestic financial and trade center in China.

\subsection{Data Acquisition and Processing}

According to the wetland definition in the Convention on Wetlands, and considering the interpretive characteristics of the

\footnotetext{
* Corresponding author
} 
remote sensing images, the wetlands of the Hangzhou Bay were classified as natural wetlands and artificial wetlands. Natural wetlands include river wetlands, lake wetlands and coastal wetlands, while artificial wetlands include reservoirs, ponds and paddy fields (Table 1). They were collected that nine cloud-free satellite images with resolution of 30 meter, covering the study area from 1996 to 2013 to investigate the temporal and spatial wetland landscape changes in Hangzhou Bay. The remote sensing images were processed by geometric correction and radiometric calibration by using ENVI 4.8. In the interpretation process, the use of 4,5 , and 3 wave band synthetic false color images, the color contrast between different landscape plates is relatively large, which is conducive to visual interpretation. The online maps from the Google Earth were able to acquire ancillary information during interpretation. A visual interpretation extracts the wetlands in these pixels around the Hangzhou Bay (Fickas et al., 2016) (Fig.2). Then evaluating the classification accuracy based on the classification method.

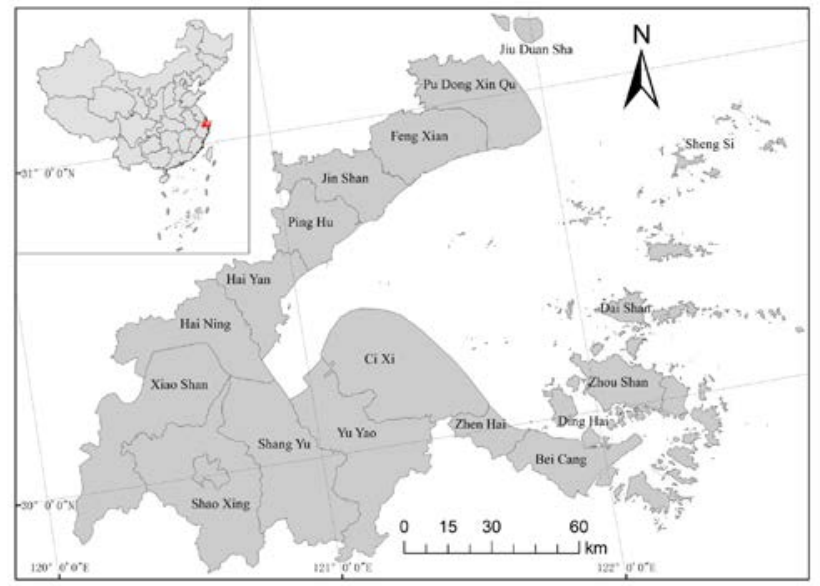

Figure 1. Location of the study area

\begin{tabular}{|c|c|c|}
\hline $\begin{array}{l}\text { Wetland } \\
\text { system }\end{array}$ & $\begin{array}{l}\text { Types of } \\
\text { wetland }\end{array}$ & Explanation \\
\hline \multirow{3}{*}{$\begin{array}{l}\text { Natural } \\
\text { wetlands }\end{array}$} & $\begin{array}{l}\text { Coastal } \\
\text { wetlands }\end{array}$ & $\begin{array}{l}\text { Plant growth including the } \\
\text { Yangtze River, coastal beach, bare } \\
\text { beach and near-shore waters }\end{array}$ \\
\hline & $\begin{array}{l}\text { River } \\
\text { wetlands }\end{array}$ & $\begin{array}{l}\text { Including permanent rivers: the } \\
\text { river bed, the reservoirs whose } \\
\text { area less than } 100 \mathrm{hm} 2 \text { in the } \\
\text { rivers }\end{array}$ \\
\hline & $\begin{array}{l}\text { Lake } \\
\text { wetlands }\end{array}$ & $\begin{array}{l}\text { Mainly including permanent } \\
\text { lakes: perennial water of fresh } \\
\text { water or salt water lake }\end{array}$ \\
\hline \multirow[t]{2}{*}{$\begin{array}{l}\text { Artificial } \\
\text { wetlands }\end{array}$} & $\begin{array}{l}\text { Reservoirs } \\
\text { and ponds }\end{array}$ & $\begin{array}{l}\text { Artificial water storage facilities } \\
\text { used for aquaculture ,flood- } \\
\text { control storage and water } \\
\text { regulation }\end{array}$ \\
\hline & $\begin{array}{l}\text { Paddy } \\
\text { filed }\end{array}$ & $\begin{array}{l}\text { Including paddy field and a small } \\
\text { part of the ground water bamboo }\end{array}$ \\
\hline
\end{tabular}

Table 1. Wetland classification system of Hangzhou Bay

\subsection{Single Dynamic Degree of Wetland Landscape}

The change rate of land uses reflects the change degree of various land use in a certain period. It can be used to quantitative description. Single dynamic degree of land use refers to the intensity of area amount changes of some kind of land use type within a certain time (Wang et al., 1999). Variations in the landscape within the study period is actually a change in land cover, they had a certain correlation. We study the dynamic degree of landscape types in Hangzhou Bay during 1996 -2013. Dynamic degree of landscape type is expressed as:

$$
K=\frac{U_{b}-U_{a}}{U_{a}} \times \frac{1}{T} \times 100 \%
$$

where $\quad K=$ dynamic degree

$U_{a}, U_{b}=$ the amount of one landscape at the beginning and the end of time period

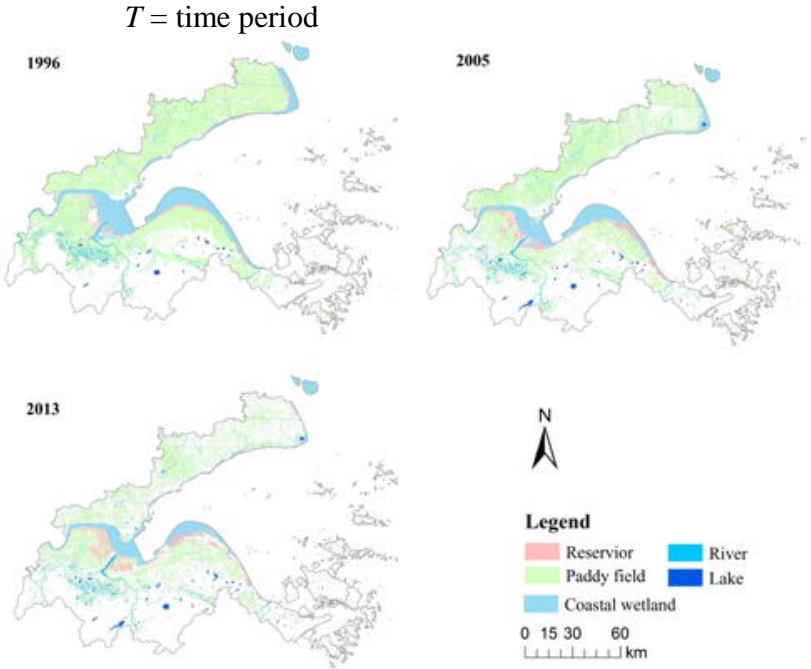

Figure 2. Distribution of wetlands in the Hangzhou Bay in 1996, 2005 and 2013

\subsection{Landscape Index}

This paper used the landscape index to study wetland pattern quantitatively in Hangzhou Bay. Landscape index refers to the quantitative indicators that highly concentrate the pattern information. It also reflects the structure and spatial distribution characteristics. Furthermore, landscape index is the digital expression of the landscape structure (Wu, 2007; Ding et al. 2003). Landscape pattern analysis refers to the description of the structural characteristics, spatial distribution patterns, distribution patterns and the relationships among the landscape elements (Xu et al., 2010). The index of the patch level and the index of landscape level were selected to investigate the characteristics of the landscape pattern of the wetland in the Hangzhou Bay.

Based on the patch class-level index, the indicators like patch type area (CA), the number of patches (NP), patch density (PD), the largest patch index (LPI), landscape shape index (LSI), average patch area (Area_MN), fractal dimension index of areaweighted mean (FRAC_AM) are mainly selected. While on the landscape-level, except to landscape division index (Division), Shannon's diversity index (SHDI), and Shannon's evenness index (SHEI). The NP, PD, LPI, and Area_MN were selected to analyze the general structure and the spatial distribution of landscape characteristics of the Hangzhou Bay. It was then investigated the law of evolution.

\section{RESULTS AND ANALYSIS}

\subsection{Evaluation of the Wetland Classification}

To ensure the reliability of the landscape classification by using unsupervised classification and visual interpretation, we also 


\begin{tabular}{lllllll}
\hline Year & \multicolumn{2}{c}{1996} & \multicolumn{2}{c}{2005} & \multicolumn{2}{c}{2013} \\
Type & Prod.Acc./\% & User Acc/\% & Prod.Acc/\% & User Acc./\% & Prod.Acc/\% & User Acc./\% \\
\hline Coastal wetlands & 87.34 & 85.47 & 89.82 & 87.03 & 86.54 & 85.75 \\
Rivers & 97.83 & 96.42 & 96.56 & 88.62 & 97.18 & 95.13 \\
Lakes & 89.73 & 83.25 & 90.92 & 86.67 & 92.21 & 90.41 \\
Reservoirs & 63.35 & 78.64 & 68.58 & 79.43 & 67.74 & 75.38 \\
Paddy field & 96.82 & 93.57 & 95.19 & 90.31 & 93.78 & 91.69 \\
Overall Acc./\% & & 81.29 & & 83.73 & & 83.94 \\
Kappa Coe./\% & & 80.16 & 81.52 & 81.86 \\
\hline
\end{tabular}

Table 2 The Hangzhou Bay wetland landscape classification accuracy evaluating (1996-2013) (\%)

\begin{tabular}{llllll}
\hline $\begin{array}{l}\text { Year } \\
\text { Type }\end{array}$ & area $/ \mathrm{km}^{2}$ & $\begin{array}{c}1996 \\
\text { ratio/\% }\end{array}$ & area $/ \mathrm{km}^{2}$ & $\begin{array}{c}2005 \\
\text { ratio/\% }\end{array}$ & area $/ \mathrm{km}^{2}$ \\
\hline Coastal wetlands & 1568.21 & 21.38 & 1183.28 & 19.46 & 905.33 \\
Rivers & 261.67 & 3.57 & 269.60 & 4.43 & 293.44 \\
Lakes & 52.30 & 0.71 & 86.33 & 1.42 & 99.87 \\
Reservoirs & 338.15 & 4.61 & 452.21 & 7.44 & 600.25 \\
Paddy field & 5113.19 & 69.72 & 4089.75 & 67.25 & 2.72 \\
Total & 7333.52 & 100.00 & 6081.16 & 100.00 & 466.87 \\
\hline
\end{tabular}

Table 3 The area $\left(\mathrm{km}^{2}\right)$ and ratio (\%) of various of wetlands from 1996 to 2013

\begin{tabular}{clllllll}
\hline Year & Type & Coastal wetlands & Rivers & Lakes & Reservoirs & Paddy field & others \\
\hline $\begin{array}{c}1996- \\
2005\end{array}$ & Coastal wetlands & 925.27 & 16.32 & 4.2 & 173.23 & 79.41 & 373.98 \\
& Rivers & 16.46 & 122.07 & 3.02 & 12.08 & 0 & 108.04 \\
& Lakes & 0 & 2.23 & 40.44 & 2.34 & 0.67 & 6.62 \\
& Reservoirs & 36.01 & 4.59 & 6.8 & 156.57 & 41.43 & 92.75 \\
& Paddy field & 95.5 & 0 & 1.98 & 41.69 & 3162.69 & 1811.33 \\
$2005-$ & Others & 110.04 & 124.39 & 34.09 & 66.3 & 805.55 & \\
2013 & Coastal wetlands & 604.63 & 2.16 & 4.71 & 103.01 & 51.24 & 417.53 \\
& Rivers & 2.16 & 131.5 & 2.82 & 25.88 & 36.53 & 70.71 \\
& Lakes & 0 & 3.4 & 68.96 & 4.26 & 0.66 & 9.05 \\
& Reservoirs & 29.34 & 12.47 & 6.83 & 238.45 & 67.63 & 97.49 \\
& Paddy field & 12.37 & 0 & 2.54 & 92.25 & 1673.34 & 2309.25 \\
& Others & 256.83 & 143.91 & 14.01 & 136.4 & 637.43 & \\
\hline
\end{tabular}

Table 4 Transition matrix of landscape types in Hangzhou Bay from 1996 to $2013\left(\mathrm{~km}^{2}\right)$

need to verify the accuracy of the classification results. The paper selected confusion matrix for accuracy evaluation. The field investigation and high resolution image on Google Earth were combined to generate surface real ROIs (region of interests). Then we matched the surface real ROIs and the classification to output the confusion matrix calculation. The confusion matrix includes the production precision and user precision of various wetlands in 1996, 2005, 2013, respectively. Besides, it also includes the overall accuracy and the kappa coefficient (Table 2). Table 2 shows that both the overall accuracy and the kappa coefficient are above 0.8, which indicates that the classifications were acceptable and reliable and the classifications could be used in subsequent studies.

\subsection{Area changes of wetland}

On the basis of the interpretation and classification of remote sensing images in the study area, the area of various wetland landscape was analyzed statistically by using ArcGIS10.1. The area and the proportion of the types of wetlands in 1996, 2005 and 2013 are shown in Table 3. Paddy fields and coastal wetlands always make up the dominant position in the Hangzhou Bay, followed by reservoirs and ponds, which accounted for a large proportion. Lakes only occupied a small ratio. The area of coastal wetland fell to about $42.3 \%$ from 1996 to 2013. The total area of river wetlands increased slightly, while there is a substantial rise in the total area of lakes, reservoirs, and ponds. Lakes grew to $99.87 \mathrm{~km}^{2}$, reservoirs, and ponds increased to $600.25 \mathrm{~km}^{2}$. From the view of the total amount of wetlands, the total area of wetland reduced by $2967.76 \mathrm{~km}^{2}$ during the period 1996 to 2013. The proportion was only $40.47 \%$, which demonstrated that the wetland of Hangzhou Bay faced a severe situation.

In order to study wetland landscape changes in Hangzhou Bay from 1996 to 2013, ArcGIS10.1 and Excel were used to the transfer matrix of various wetlands during 1996-2005 and 2005-2013, respectively. The results are shown in Table 4.

Based on the analysis of the transfer matrix of Hangzhou Bay during 1996-2005 and 2005-2013, the change characteristics of the region can be concluded as follows: The transformations of Hangzhou Bay wetland are mainly among coastal wetland and paddy field and others during 1996-2005. The coastal wetland drastically transformed to reservoirs and ponds, followed by the transformation between paddy field and coastal wetland. Besides, the transformation is also evident between reservoirs, ponds and paddy field. 
The changes of the wetland are still mainly among coastal wetland and reservoirs, ponds, and paddy field during 20052013. The transformation between coastal wetlands, reservoirs, and ponds are intense. The trend of decrease is slowing down in whole area. Followed by the transformation between paddy field and coastal wetland, the total area sees a downward trend. Besides, the transformation between reservoirs, ponds and paddy field is also obvious.

In general, a quite similar situation lies on the transfer directions. Large amounts of the coastal wetlands and the paddy fields both convert into non-wetlands in 1996-2005 and 2005-2013. But there are still some differences in the transfer degree during these two periods.

It is also necessary to be mentioned that, according to Formula 1 and the data from Table 3, landscape dynamics of the Hangzhou Bay can be drawn (Table 5). Through analyzing the wetlands of Hangzhou Bay during 1996-2013, lakes grow the fastest with $\mathrm{K} 5.35 \%$, followed by reservoirs and ponds with $\mathrm{K}$ $4.56 \%$. On the other hand, paddy fields reduce fastest with $\mathrm{K}$ $3.04 \%$, followed by coastal wetlands with $\mathrm{K} 2.49 \%$. The area of river wetlands grow slowly and its average annual change rate is $0.71 \%$. It has little change and become the most stable wetland landscape.

\begin{tabular}{llll}
\hline Type & $\mathrm{Ua} / \mathrm{km}^{2}$ & $\mathrm{Ub} / \mathrm{km}^{2}$ & $\mathrm{~K} / \%$ \\
\hline Coastal wetlands & 1568.21 & 905.93 & -2.49 \\
Rivers & 261.67 & 293.44 & 0.71 \\
Lakes & 52.30 & 99.87 & 5.35 \\
Reservoirs & 338.15 & 600.25 & 4.56 \\
Paddy field & 5113.19 & 2466.87 & -3.04 \\
\hline
\end{tabular}

Table 5 The dynamic degree of landscape types

\subsection{Changes of Wetland Landscape Pattern}

The patch class-level index in 1996, 2005 and 2013 were further obtained through Fragstats3.3 to get various patch class-level index of the Hangzhou Bay during 1996-2013, which is shown in table 6. The results revealed that the CA of coastal wetlands and paddy fields declined since 1996, while the total patch area of rivers, lakes, reservoirs and ponds increased. Except the river wetlands, the NP of all the other wetlands increased. The PD of all the wetlands increased, and the rise in lakes, reservoirs, ponds and paddy fields were dramatic. They reached at $312.29 \%, 370.66 \%, 475.11 \%$, respectively. However, the LPI of paddy fields decreased by $77.86 \%$, the Area_MN decreased by 86.10 . that the degree of fragmentation in paddy fields increased, landscape dominance gradually lost. The NP and PD of lakes, reservoirs and ponds increased faster than that of the total area. The mean patch of the two wetlands showed a decreasing trend. It indicated that the lakes, reservoirs and ponds faced further fragmentation.

The Table 7 showed that the NP increased from 29005 in 1996 to 71149 in 2013. The PD increased from 4 per hectare in 1996 to 16.37 per hectare in 2013 and the Area_MN decreased to $6.11 \mathrm{hm} 2$ in 2013 from $24.98 \mathrm{hm} 2$ in 1996, indicating that the decline in the LPI is also very obvious. The value of LSI was 0.88 in 1996. The Division increased significantly in 2013, and it almost reached 1. The PN and PD of Hangzhou Bay increased, but Area_MN reduced, which means that regional landscape fragmentation is broken down. The value of Division was large and gradually increased, almost close to 1 , which indicating that the landscape in the region has been in high fragmentation, and this fragmentation was increased in the estimated time period. It can be seen from Table 8 that the SHDI in 1996 was 0.87, and gradually increased. The SHEI also increased from 0.54 in 1996 to 0.74 in 2013, which also showed that the landscape patterns, fragmentation degree and the landscape homogenization increased.

\begin{tabular}{llllll}
\hline Year & NP & PD & LPI & $\begin{array}{l}\text { AREA } \\
-\mathrm{MN} /\end{array}$ & DIVISION \\
\hline 1996 & 29005 & 4.00 & 27.64 & 24.98 & 0.88 \\
2005 & 42131 & 6.95 & 26.46 & 14.39 & 0.92 \\
2013 & 71149 & 16.37 & 7.98 & 6.11 & 0.98 \\
\hline
\end{tabular}

Table7 Landscape shape pattern index of Hangzhou Bay

\begin{tabular}{ccc}
\hline Year & SHDI & SHEI \\
\hline 1996 & 0.87 & 0.54 \\
2005 & 0.97 & 0.61 \\
2013 & 1.19 & 0.74 \\
\hline
\end{tabular}

Table 8 Landscape diversity index of Hangzhou Bay

\subsection{Analysis of related factors in wetland landscape changes}

Wetland landscapes influenced both by human and natural factors. Since 1995, with the progress of urbanization, the change of wetland area was affected by human factors such as reclamation projects. At the same time, its changes affected by natural factors such as climate change and sea level. Urbanization, reclamation of wetlands, coastal erosion, sea levels rising and water pollution are all major threats to wetlands.

\begin{tabular}{lllllllc}
\hline Type & CA/\% & NP/\% & PD/\% & LPI/\% & LSI/\% & AREA_MN/\% & FRAC_AM/\% \\
\hline Coastal wetland & -39.46 & 45.28 & 142.12 & -0.03 & 45.98 & -58.33 & -1.85 \\
River & 12.25 & -7.60 & 53.97 & 51.05 & 1.67 & 21.49 & -1.67 \\
Lake & 91.44 & 147.37 & 312.29 & 147.97 & 46.10 & -22.61 & 0.82 \\
Reservoir & 81.30 & 182.41 & 370.66 & 610.26 & 49.53 & -35.80 & 1.40 \\
Paddy field & -52.03 & 245.09 & 475.11 & -77.86 & 78.23 & -86.10 & -7.49 \\
\hline
\end{tabular}

Table 6 Variations of the patch class-level index of the wetland in the Hangzhou Bay 
3.4.1 Human Factors: Table 4, transition matrix of landscape types show that the largest conversion area of various types of wetlands is the other types of land. Part of it is the type of urban land use. The rapid development of cities near Hangzhou Bay has generally increased the urbanization rate over the past 20 years. The most typical of them was Shanghai (Bureau, 2014), with an urbanization rate of $70.8 \%$ in 1996, an increase of $80.5 \%$ in 2005 and an urbanization rate of $90 \%$ in 2013. Followed by Hangzhou (Bureau, 2014), its rate grew from $32 \%$ in 1996 to $55 \%$ in 2013 . More than half of the population was non-agricultural population. The economic development of the Hangzhou Bay urban agglomeration is also fast, with the regional gross domestic product (GDP), per capita GDP and industrial output steadily rising. From 1996 to 2013, the GDP of six cities (Bureau, 2014) around Hangzhou Bay increased by 6 to 8 times. Among them, Shanghai saw the largest increase, amounting to 18699.92 trillion yuan. The per capita GDP of these cities increased from about 10,000 yuan to about 90,000 yuan. The total value of industrial production showed the same trend and increased significantly. Population growth and economic development have brought tremendous demand for land resources. The built-up area is the main type of land for urban use and the area increased in recent years dramatically. The area of built-up area of Shanghai in 2000 was $342.06 \mathrm{~km}^{2}$, nearly doubling in five years and the area of builtup area was over 3 times by 2013, reaching $1106.85 \mathrm{~km}^{2}$. Apart from Shanghai, the built-up areas of other cities around the Hangzhou Bay urban agglomeration, Jiaxing, Hangzhou, Shaoxing, Ningbo and Zhoushan have all increased significantly, from 1996 to 2013, which steadily doubled in eight years. The acceleration of urbanization led to the expropriation of wetland resources and the reduction of wetland area. Shanghai, the city with the fastest urbanization, has provided more than 100,000 hectares of land resources to coastal and coastal wetlands since the founding of new China. The land area of Shanghai has expanded by 15\%, which provides a great space for the development of industrial and agricultural production and urban construction in Shanghai (Cai et al., 2014).

The main reason for the sharp decline in the area of natural wetlands is the change in the use of natural wetlands and the occupation of natural wetlands by urban development, especially in swamps and coastal areas. For a long period, people have destroyed large areas of wetland tidal flats in order to obtain more usable land, resulting in the fragmentation of the wetland landscape. Some wetlands wastelands of river reclaimed as agricultural land, resulting in tremendous economic benefits. Economic activities, such as reclamation of land from the lake and sea, directly reduce wetland area. During the process of urban construction, a large number of reclaimed wetlands and natural wetlands converted into constructed wetlands. From 1995 to 2005 and from 2005 to 2013, the types of coastal wetlands of $173.23 \mathrm{~km} 2$ and 103.01 $\mathrm{km} 2$, respectively, converted into ponds. The area converted from various types of wetlands to other types of land use was $2392.72 \mathrm{~km} 2$ and $2904.03 \mathrm{~km} 2$ respectively, while from other types of land use changed to wetland types was $1140.37 \mathrm{~km} 2$ and $1188.58 \mathrm{~km} 2$. The net area converted from other types of wetlands was $1252.35 \mathrm{~km} 2$ and $1715.45 \mathrm{~km} 2$, respectively. Taking Shanghai as an example, it all based on reclamation of tidal flat resources that Jinshan's Caojing Chemical Base, Pudong Airport, Pudong Sanjiagang Huaxia Cultural Tourism Zone and Fengxian South Shanghai Water Park. As well as travel and leisure purposes, such as Jinshan City Beach and
"Clear Water, Blue Sands" Beach in Fengxian District and so on, are built on this basis.

In addition, pollution is one of the threats to wetlands. With population growth, industrial and agricultural production and the expansion of urban construction, a large amount of domestic sewage, industrial wastewater and agricultural wastewater are discharged into wetlands. These pollutants not only cause serious damages to the biodiversity of the wetlands, but also affect the ecological environment of the wetlands that bring negative effects. Furthermore, natural wetlands in some areas have become the recipients of industrial, agricultural and domestic sewage. The heavy use of fertilizers and pesticides polluted wetlands heavily. In spite of the decontamination function of wetlands, the discharge of large amounts of sewage, especially wastewater containing large amounts of inorganic chlorine and inorganic phosphorus nutrients, can cause the wetlands to lose their purification function and result in the eutrophication of the water body.

3.4.2 Natural factors : In the past 20 years, in the cities around Hangzhou Bay, the precipitation showed a stable trend except for slight fluctuations, which did not cause an obvious impact on the total amount of water supplied to wetland ecosystems. The average annual temperature rose slightly with global warming trends. The global warming caused the sea level to rise and the sea level of Hangzhou Bay increased too. However, the cities around Hangzhou Bay had a lower altitude. Seawater submerged some wetlands with low-level and their area was reduced. The rise of temperature makes the evaporation increase, which could not fully meet the water demand of wetland ecosystem and restrain the growth of wetland vegetation such as reed and Spartina alterniflora on the coast of Hangzhou Bay estuary. In addition, the diversion of rivers affected the supply of water to the wetlands by the rivers, to a certain extent, damaging some of the lake wetlands. Coastal erosion is also a factor in the reduction of wetland area due to the erosion of the northern bank of Hangzhou Bay and the coastline receding.

\section{CONCLUSION AND DISCUSSION}

The wetland landscape classification maps in there period were obtained through interpretation based on the remote sensing images of Hangzhou Bay in 1996, 2005 and 2013. According to the classification results, the area of various wetlands, this paper obtained that transfer matrix of wetland area, signal dynamic of landscape pattern and landscape index to analyze the landscape pattern and the changes in the Hangzhou Bay. Furthermore, the paper can provide some guidance to the utilization and protection of wetland in the Hangzhou Bay. The main conclusions as follows: (1) the total area of the wetland in the Hangzhou Bay decreased. Especially, the total area of coastal wetlands and paddy fields reduced greatly. The area of reservoirs and ponds showed a trend of substantial growth, and some paddy fields turned into non-wetlands, such as construction lands. (2) The transfer matrix showed that the transformations between coastal wetlands, the reservoirs and ponds in Hangzhou Bay were much more intense, while the transformations between reservoirs, ponds and paddy fields were obvious. Transformations of the former had a certain association with the changes of the coastal zone. The latter is mainly due to the local policies in the development of the aquaculture industry. In addition, it was evident that large amounts of wetland converted into non-wetland, such as 
construction land, which was due to the rapid urbanization in this region. (3) The landscape index showed that the NP, PD, LSI, SHDI and SHEI were generally in the rising trend. The LPI and Area_MN were in the decreasing trend, which indicating that the wetland landscape fragmentation, landscape types and landscape evenness of Hangzhou Bay increased. (4) The rapid urbanization of the cities around Hangzhou Bay makes the distribution, structure and function of wetlands change constantly, the biological resources of wetlands overuse and the artificial trend of wetlands accelerate. Moreover, the tidal flat reclamation resulted in the decrease of the total amount and proportion of coastal and coastal wetlands. In addition, coastal erosion, global climate change, water quality and heavy metal pollution, etc., contribute to the reduction of wetland resources. Among them, population pressure is the most fundamental reason for the degradation of wetlands.

As large study area and long time span of this paper, it is hard to obtain high-resolution remote sensing images. Moreover, the resolution of Landsat TM remote sensing image is $30 \mathrm{~m}$, and it brought some difficulties to extract the wetland landscape. Furthermore, the classification system in this paper is not exhaustive since it only extracted the wetland and did not involve in construction land and unused land. Thus, the analysis of changes of wetland landscape cannot be done indepth and thoroughly. Our future investigation will attempt to select a typical study area in a small range, combining with a variety of data like high-resolution remote sensing images and the land use map, and improving the precision and the detail of the landscape classification.

\section{ACKNOWLEDGEMENTS}

This work was supported by National Natural Science Foundation of China (No. 41571047), National Natural Science Foundation of China (Key Program: No. 41730642), and National Key Research and Development Program of China (No.2016YPC0502706).

\section{REFERENCES}

Bai, J.H., Ou, Y.H., Yang, Z.F., Cui, B., Cui, L., and Wang, Q., 2005. Changes in wetland landscape patterns: A review. Progress in Geography, 24, pp. 36-45.

Batzer, D.P., and Sharitz, R.R., 2006. Ecology of freshwater and estuarine wetlands. Univ of California Press. pp. 35-83

Blackwell, M.S., and Pilgrim, E.S., 2011. Ecosystem services delivered by small-scale wetlands. Hydrological Sciences Journal, 56(8), pp. 1467-1484.

Bureau, J. S. (2014). Statistical Yearbook of Jiaxing. Beijing: China Statistics Press http://www.jxstats.gov.cn/list.aspx?id=740858076834

Bureau, H. S. (2014). Statistical Yearbook of Hangzhou. Beijing: China Statistics Press http://tjj.hangzhou.gov.cn/

Bureau, N. S. (2014). Statistical Yearbook of Ningbo. Beijing: China Statistics Press http://tjj.ningbo.gov.cn/tjnj/2004njbg.htm
Bureau, S. S. (2014). Statistical Yearbook of Shanghai. Beijing: China Statistics Press http://www.statssh.gov.cn/html/sjfb/201701/1000200.html

Bureau, S. S. (2014). Statistical Yearbook of Shaoxing. Beijing: China Statistics http://tjj.sx.gov.cn/col/col64/index.html

Bureau, Z. S. (2014). Statistical Yearbook of Zhoushan. Beijing: China Statistics http://www.zstj.net/Tjnj/Category.aspx

Cai, Y.M., and Zhou, Y.X., 2014. Shanghai wetlands. Shanghai Scientific \& Technical Publishers, pp. 1-3

Costanza, R., d'Arge, R., De Groot, R., Farber, S., Grasso, M., Hannon, B., and Raskin, R. G., 1997. The value of the world's ecosystem services and natural capital. Nature, 387(6630), pp.253-260.

De la Hera, A., Fornés, J. M., and Bernués, M., 2011. Ecosystem services of inland wetlands from the perspective of the EU Water Framework Directive implementation in Spain. Hydrological sciences journal, 56(8), pp. 1656-1666.

Ding, S.Y, and Liang, G.F., 2004. Landscape pattern change of regional wetland along the Yellow River in Henan Province in the last two decades. Acta Geographica Sinica, 59(5), pp. 653661.

Ding, S., Qian, L., Cao, X., LI, S., and LI, H., 2003. Forest landscape patterns dynamics of Yihe-Louhe River basin. Acta Geographica Sinica, 58(3), pp. 354-362.

Fang, X. Q., Ye, Y., Ge, Q. S., and Zheng. J. Y., 2011. Views of Some Basic Problems on Wetland Researches. Progress in Geography, 20(2), pp. 177-183.

Fan Q, and Du T, 2014. Landscape pattern changes for Nansihu wetland from 1982 to 2012. Resources Science, 36, pp.865-873

Fickas, K. C., Cohen, W. B., and Yang, Z., 2016. Landsatbased monitoring of annual wetland change in the Willamette Valley of Oregon, USA from 1972 to 2012. Wetlands ecology and management, 24(1), pp.73-92.

Ghermandi, A., Van Den Bergh, J. C., Brander, L. M., de Groot, H. L., and Nunes, P. A., 2010. Values of natural and humanmade wetlands: A meta-analysis. Water Resources Research, 46(12).

Horwitz, P., and Finlayson, C. M., 2011. Wetlands as settings for human health: incorporating ecosystem services and health impact assessment into water resource management. BioScience, 61(9), pp. 678-688.

Kayastha, N., Thomas, V., Galbraith, J., and Banskota, A., 2012. Monitoring wetland change using inter-annual landsat time-series data. Wetlands, 32(6), pp.1149-1162.

Liu, H.Y., Li, Y.F., and Cao, X., 2009. The current problems and perspectives of landscape research of wetlands in China. Acta Geographica Sinica, 64(11), pp. 1394-1401.

Niu, M. X., Zhao, G. X., and Li, Z. Y., 2004. Extracting of remote sensing information of wetland in Nansihu area based 
on multi-sub area and multi-layer techniques. Geography and Geo-Information Science, 20(2), pp. 45-48.

Wang, X.L., and Bao, Y. H., 1999. Study on the methods of land use dynamic change research. Progress in Geography, 18(1), pp. 81-87.

Wu, J.G., 2007. Landscape ecology: pattern, process, scale and hierarchy. Bejing: Higher Education Press, pp.96-100

Xu, Y.D., Fu, B.J., and Lü, Y., 2010. Research on landscape pattern and ecological processes based on landscape models. Acta Ecologica Sinica, 30(1), pp. 214-222.

Zedler, J. B., and Kercher, S., 2005. Wetland resources: status, trends, ecosystem services, and restorability. Annu. Rev. Environ. Resour., 30, pp. 39-74. 